\title{
Undergraduate Education in the Knowledge School
}

\author{
Elise C. Lewis
}

University of South Carolina

\begin{abstract}
The idea of a Knowledge School requires rethinking many aspects of how we approach the curriculum and our students. This article outlines the changes and revisions made the undergraduate curriculum to under the umbrella of the Knowledge School.
\end{abstract}

Keywords: undergraduate education, curriculum, integrated learning

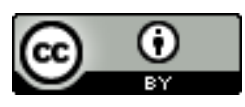

This is an Open Access article distributed under the terms of the Creative Commons Attribution 4.0 International License (http://creativecommons.org/licenses/by/4.0), which permits unrestricted use, distribution, and reproduction in any medium, provided the original work is properly cited. 
One of the most important components of the Knowledge School is its students. Our priority is to ensure that students graduating from our program can not only work in information environments but lead and contribute. An obvious place to add these values and ideas is the curriculum. Faculty, staff, and students routinely conduct curriculum reviews after milestones such as accreditation. In connection with the launch of the Knowledge School, the faculty noted the convergence of several factors highlighting the need for curriculum revisions. How do we make sure our students understand our definitions and apply those definitions to the field? How do we make sure these ideas translate to marketable and desired skill sets demanded by employers? This section will discuss the motivations, processes, and ongoing activities involved with linking the curriculum and the ideology of the Knowledge School.

The faculty created the information science undergraduate program (BSIS) in 2008. Over the years, they added courses to the curriculum in order to update the skillsets of the students. However, a complete program review had not been done for some time. David Lankes' arrival as director of the school prompted questions regarding the growth of the undergraduate program and placement of our students after graduation. It became apparent that it was time to review the program and explore new opportunities that could arise when launching an updated version of the program. The faculty updating the curriculum would focus on revisions by Knowledge School influences.

In the fall of 2016, work began on the program overhaul. The faculty identified needs and opportunities through discussions, site visits, and focus groups. The communities we approached with these ideas and questions included other undergrad programs, our local and national partners, and potential employers. One thing became very clear during this process: our students must be comfortable working in constantly changing information environments. These settings often present 
high levels of ambiguity and uncertainty. How we prepare our students for those types of settings (not easily replicated in the classroom) emerged as the important task.

Keeping these issues in mind, the faculty began revising our mission and goals and then turned our intention to the curriculum. Right away, we discovered that we, as faculty and staff, did not have a common understanding of the terms we use to teach our students. How were we going to develop a program and curriculum if we weren't using the same terms? After several meetings, side discussions, campaigning, and work days, we finally agreed upon the terms. The codified definitions provided us a foundation to build upon and a common language that had been missing.

We began the process of reviewing and revising the curriculum armed with the common terms and an understanding of what would be expected from our students after graduation. It is worth noting that the process of changing a curriculum at the University level is not quick. One of the goals of a curriculum review process is to ensure that the curriculum is current and also is adaptable to future needs. Curriculum reviews, at a smaller scale, will likely happen every 1-2 years.

The Knowledge School efforts on socially just, community-based, practitioner-informed, and influenced knowing require different approaches at the various degrees. The revised BSIS curriculum was implemented in the Fall 2018. We recently achieved accreditation through the American Library Association accreditation process for our Master of Library and Information Science. Work has begun on the MLIS curriculum review. The following year we will do the same for the PhD program. The following are aspects we emphasize when incorporating the Knowledge School ideas into the curriculum.

\section{Developing community partnerships for meaningful interactions}


- Undergraduate students are required to have internships or independent studies where they work with community partners. Service-learning courses, where community partners are brought into the classroom, are offered. Partners bring practical problems to classrooms and work with our students to find solutions.

- For MLIS students, community partnerships are vital to gaining hands-on experience and learning about different information environments.

- Doctoral students are encouraged to work with community partners in a research context.

- We have also established speaker series to invite community partners into the school and interact with our students.

\section{Emphasizing integrative learning experiences}

- Connecting within-the-classroom learning with opportunities to learn outside of the classroom

- Encouraging undergraduates to participate in the campus initiatives that recognize the importance of leadership and learning outside of the classroom. This helps demonstrate the breadth of the student's skill set, as well as leadership capabilities. It also helps employers understand the potential of a degree in Information Science by highlighting their work.

- Doctoral students take courses on pedagogy and are then put into the classrooms.

The faculty-led curriculum review was critical after the infusion of the Knowledge School influences. The changes not only benefited the students but also allowed for new approaches to teach evolve. This type of review will be done routinely for an up-to-date curriculum and better prepared graduate. 